\title{
Aférese e prótese: verso e reverso fonológico
}

\section{CARLOS ALEXANDRE V. GONÇALVES Universidade Federal do Rio de Janeiro}

\section{Abstract}

By taking the phenomena of dropping (aphaeresis) and addition (prosthesis) of inicial $/ \mathrm{a} /$ as the chief point in a diffusionist inquiry, this article intends to discuss two main points. First, we analyse the most relevant characteristics of the phenomena in question as well as the typology of the initial segments we have found out. Our purpose is to present a morphological salience scale as the chief refraining agent of change. Secondly, we analyse the results of the tested lexical parameters and assume the hypothesis of the Inverse Proportionateness of the phenomena which, like a play on equivalences in a mirror, spread simetrically through the lexicon. 


\section{ASPECTOS DA MUDANÇA EM /a/ INICIAL}

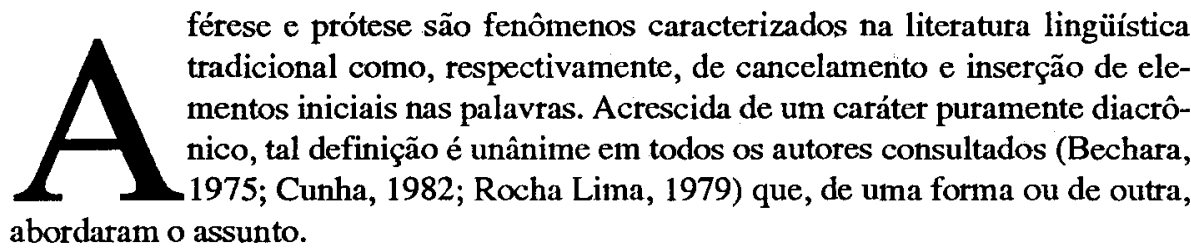

Diferentemente da prática tradicional, analisaremos estes fenômenos de metaplasmos (a) na fala e (b) do ponto de vista sincrônico, adotando, como aparato teórico, os pressupostos da Difusão Lexical. Para tanto, utilizaremos, como corpus de análise, as 64 horas de fala carioca que compóem a Amostra Censo de Variação Lingüística.

Para relacionar os dois fenômenos entre si, optamos por trabalhar, aqui, somente com casos em que o contexto estrutural no qual os dados de aférese e prótese se inserissem fossem semelhantes, visto encontrarmos, na fase de coleta, dados com segmentos iniciais variáveis de natureza bastante diversificada (como, por exemplo, "es" em 'esta/tá' e "o" em 'obrigado/brigado"), que merecem um tratamento à parte, devido à sua própria natureza estrutural. Dai trabalharmos apenas o segmento /a/ inicial, comum aos dois fenômenos, o que possibilita uma testagem em parâmetros comuns. Na Fig. 1, a seguir, esquematizamos a natureza estrutural variável da aférese e da prótese. Em seguida, exemplificamos os dois fenômenos, em (1) e (2), para a aférese e para a prótese, respectivamente.

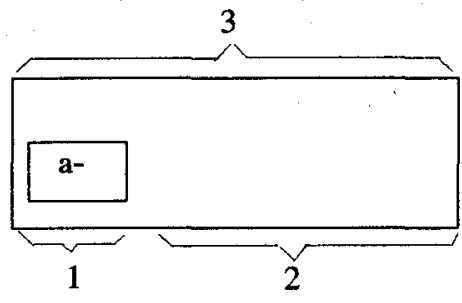

1. cadeia variável $(1 \sim \phi)$

2. cadeia permanente

3. vocábulo

FIGURA 1 
(1) Depois, não ødianta mais nada, né?

(NIL (12), 46 anos, primário)

(2) A gente comprou papel Acelofane pra embrulhar os presente.

(JUP (06), 22 anos, primário)

Este/a/com que trabalhamos pode ou não apresentar um valor mórfico, istoé, pode ou não ser prefixo. Desta forma, elaboramos, de acordo com a motivação semântica desse segmento, uma tipologia para os vários casos de /a/ encontrados. Por outro lado, essa tipologia só é válida para o fenômeno da aférese, uma vez que o /a/ protético é uma espécie de "intrusão" e não acrescenta, em princípio, nenhum valor mótfico, nenhuma função especifica.

Arrolamos, com base nos dados, quatro tipos de /a/ inicial: a) prefixos semânticos, em que o segmento inicial é o elemento mórfico responsável pela oposição semântica entre duas formas da lingua (como em 'anormal' e 'assistemático'); b) prefixos assemånticos, cujos segmentos iniciais não são dotados de conteúdo semântico, mas de valor relacional, transformando classes gramaticais ('anoitecer' e 'apunhalar'); c) prefixos etimológicos, em que o/a/ somente funciona como morfema quando a análise leva em conta o aspecto diacrônico ('advogado' e 'absurdo') e d) não prefixos, quando destituídos de qualquer caráter morfológico (como, por exemplo, em 'apanhar' e 'ajudar').

$\mathrm{Na}$ anảlise multivariacional atribuínos uma escala de "saliência mórfica" para o /a/ inicial que, na ordem acima apresentada, descresce de a) a d), isto é, prefixos de negação são mais salientes do que prefixos assemânticos (funcionais) que, por sua vez, são mais salientes que os prefixos etimológicos e estes mais salientes que aqueles sem valor mórfico, assim:

pref. neg. 3 pref. assem. 2 pref. etimol.

1 sem valor mórfico

$\varnothing$

Quando o/a/ inicial é prefixo de negação, agregando-se a um radical para, a partir dele, formar uma nova palavra, imprimindo-lhe uma idéia diametralmente oposta àquela apresentada pelo radical inicial, ele nunca sofre afetamento. Esta condição para a aplicação da regra de presença de /a/ revela um caso em que as exceções à mudança não podem ser explicadas nem por anologia, nem por empréstimos, mecanismos advogados como refreadores pela tese neogramática, mas por um fator estritamente morfológico que funciona como "freio", no sentido de preservar a forma antiga e resistir à mudança. A Tabela 1 mostra que o grau de afetamento por aférese aumenta à medida que se diminui a escala de saliência mórfica. 
TABELA 1

A escala da saliência morfológica do/a/ e grau de afetamento por aférese

\begin{tabular}{c|c|c|c|c}
\hline & grau de saliência & Apl/total & $\%$ & prob. \\
\hline pref. assemat. & 2 & $105 / 391$ & 26 & .35 \\
pref. etimol. & 1 & $21 / 83$ & 25 & .49 \\
não prefixos & $\varnothing$ & $582 / 1617$ & 36 & .76 \\
\hline
\end{tabular}

Os resultados na Tab. 1, além de satisfazerem (e comprovarem) a escala de saliência mórfica, mostram o percurso motfológico da mudança $\mathrm{em} / \mathrm{a} /$. Sob variações condicionadas tanto do ponto de vista lingüistico quanto extralingüístico, este fenômeno está se infiltrando no sistema da língua atingindo primeiramente os itens lexicais em que o/a/nãoé signo mínimo, para depois, numa escala gradual de saliência mórfica, atingir o léxico em que o/a/ inicial possui algum traço de significação morfológica. A causa dos resíduos/barreiras lexicais da inovação em estudo (a queda do/a/ inicial) se prende a um fator de natureza morfo-lexical: quando um vocábulo possui prefixo de negação, ele nunca sofre afetamento por aférese.

\section{AFÉRESE E PRÓTESE E A DIFUSÃo LEXICAL}

Em trabalho anterior (Gonçalves, 1989) constatamos que os fenômenos de aférese e prótese não atingem todo o léxico de dados potencialmente afetáveis, fato que, por si só, já se constitui em contra-argumento à redutora visão neogramática. No modelo dos "Junggrammatiker", a ausência de exceções às mudanças sonoras é aparentada aos desvios de linguagem que a gramática tradicional considera como obra do acaso ou arbitrariedade.

Não nos cabe, aqui, retomar a controvérsia e o debate das teses neogramática e difusionista sobre as mudanças fonéticas. Antes, queremos mostrar como os postulados da Difusão Lexical proporcionam relacionar dois fenômenos inversos, de modo a vê-los como cara e coroa de uma mesma moeda fonológica. Assim, pretendemos utilizar o modelo difusionista para verificar se afẻrese e prótese, através da metáfora do enantiomorfismo da imagem de um espelho, refletem-se entre si, testando-lhes variáveis próprias do léxico, no intuito de conferir-lhes princípios propulsores ou reguladores da mudança.

Antes de passarmos à análise dos parâmetros lexicais testados, faz-se necessário estabelecer algumas peculiaridades do léxico envolvido na amostra.

Em primeiro lugar, o léxico com que lidamos é bastante limitado: além de serem poucos os itens envolvidos, também é baixo o seu grau de afetamento. Essa situação fica ainda mais delimitada se compararmos os dois fenômenos - os itens são mais afetados por aférese do que por prótese (29\% de variação no primeiro, contra $14 \%$ no segundo) - o que revela a ação do principio de economia da língua. A lei do menor esforço, neste caso, parece atuar como agente refreador da mudança protética, no intuito de inibir a inserção do $/ a /$. 


\section{Categoria Gramatical}

Tentando verificar a influência da variável Categoria Gramatical - que também se mostrou relevante em diversos trabalhos que seguem a orientação difusionista, como o de Lima (1990) e o de Mollica \& Mattos (1990) - nos fenômenos aqui investigados, procedemos a uma divisão que distribuiu os dados afetados e potencialmente afetados em cinco classes de palavras: verbos (apanhar/sujeitar), adjetivos (acabado/viciado), substantivos (abacaxi/celofane), advérbio (agora/ainda), e preposições (até/ apesar (de)), nesta ordem. Considerem-se os resultados das Tab. 2 e 3:

\section{TABELA 2}

Relação entre afetamento por aférese e Categoria Gramatical

\begin{tabular}{c|c|c}
\hline \multicolumn{3}{c}{ Itens afetados } \\
Total de itens & $\%$ \\
\hline Verbos & $47 / 117$ & 40 \\
Adjetivos & $10 / 40$ & 25 \\
Substantivos & $13 / 53$ & 23 \\
Advérbios & $2 / 11$ & 18 \\
Preposições & $1 / 7$ & 14 \\
\hline
\end{tabular}

TABELA 3

Relação entre afetamento por prótese e Categoria Gramatical

\begin{tabular}{c|c|c}
\hline \multicolumn{3}{c}{ Itens afetados } \\
Total de itens \\
\hline Verbos & $26 / 64$ & 48 \\
Adjetivos & $7 / 21$ & 33 \\
Substantivos & $2 / 11$ & 18 \\
Advérbios & - & - \\
Preposiçóes & - & - \\
\hline
\end{tabular}

Observe-se que o índice de afetamento por aférese - Tab. 2 - e por prótese - Tab. 3 - decresce à medida que se passa, na ordem acima apresentada, dos verbos às preposições. Ora, é claro o fato de estarmos diante de sistemas abertos e fechados. Os verbos, os adjetivos e os substantivos constituem classes abertas de palavras, enquanto que advérbios (exceção feita aos de sufixação em - mente, os chamados nominais) e preposições fazem parte de um sistema fechado. Parece razoável adınitir que o grau de afetamento seja maior nos sistemas abertos, pois estes são o universo infinito da língua, uma vez que vivem em permaniente expansão para incorporar novas experiências. $\mathrm{O}$ mesmo não se dá com os advérbios e com as preposições que, em númeto limitado na lingua, são as "palavras-ferramenta" que funcionam apenas dentro do próprio sistema. Dai termos, como classes predominantemente atingidas pelos fenô- 
menos de aférese e prótese, a dos verbos, adjetivos e substantivos, todas pertencentes ao léxico da lingua propriamente dito, em ordem decrescente de afetamento.

É razoável admitir que o sistema fechado funcione como agente refreador da mudança em /a/ inicial. Mas, por outro lado, a que atribuir o fato de os verbos constituírem a classe morfológica predominantemente afetada por apagamento/inserção de /a/ inicial, se também adjetivos e substantivos fazem parte do inventário aberto da língua?

No caso dos substantivos, os trabalhos em linha difusionista, como os de Oliveira (1991 e 1990), têm atestado que esta classe atua como inibidora em inúmeros fenômenos de mudança. De fato, os nomes próprios podem preservar a forma antiga e resistir à mudança. Nas aféreses, dos treze substantivos afetados, onze são comuns (abacaxi, administrador, advogado, aeronáutica, aipim, amamentação, aniversário, apartamento, arraia, avental e avião) e apenas dois são próprios (Alexandre e Adelaide). Também nas próteses o fato se repete: os dois substantivos afetados são comuns (celofane e punhalada), o que mostra que os substantivos próprios são menos propensos à mudança.

Os resultados das Tab. 2 e 3 lançam mais questões: por que todos os adjetivos afetados são deverbais? $E$ mais, por que os adjetivos afetados têm, no corpus, um correspondente verbal que, por sua vez, também sofre afetamento? De fato, todos os adjetivos atingidos por aférese e por prótese têm um correspondente verbal também atingido: em 'abitolado', por exemplo, há a forma verbal 'bitolar', assim como em 'repiado', há o correspondente 'arrepiar'. Parece que a influência dos verbos como classe propulsora à mudança é maior que imaginamos. Será que as primeiras vítimas de aférese e prótese foram verbos?

Uma análise via Tempo Aparente não dá conta de um diagnóstico preciso dos fenômenos de mudança, conforme já advogava Labov (1981). Somente com o controle dos dados de aférese e prótese em dois tempos é que se torna possível identificar uma rota seguida pela mudança em /a/ inicial, verificando suas primeiras vítimas?

Desta forma, analisamos os fenômenos em dados de fala da Amostra Censo em dois estágios de tempo diferentes: os informantes do "Censo" de 1982 foram revisitados pela equipe do PEUL em 1988, no intuito de fornecer um arquivo de dados para estudos sociolingüísticos via Tempo Real, embora reconhecendo que o espaço de tempo entre os dois corpora não seja o ideal. A Amostra de 1988 é composta por doze informantes cariocas: seis homens e seis mulheres, cujas idades variam de 21 a 66 anos, conforme mostra a Tab. 4:

\section{TABELA 4}

Amostra Censo em dois tempos: 1982 e 1988

1982

\begin{tabular}{c|c|c|c|c|c|c|c|c}
\hline idade & \multicolumn{2}{|c|}{ primário } & \multicolumn{2}{|c|}{ ginásio } & \multicolumn{2}{c|}{$2^{2}$ grau } & \multicolumn{2}{|c}{ universitário } \\
\hline & $\mathrm{H}$ & $\mathrm{M}$ & $\mathrm{H}$ & $\mathrm{M}$ & $\mathrm{H}$ & $\mathrm{M}$ & & \\
$15-30$ & 1 & - & 1 & 1 & 1 & 2 & & \\
$31-50$ & - & - & 1 & - & 1 & 1 & & \\
+50 & 1 & - & 1 & - & - & 1 & & \\
\hline
\end{tabular}


1988

\begin{tabular}{c|c|c|c|c|c|c|c|c}
\hline & $\mathrm{H}$ & $\mathrm{M}$ & $\mathrm{H}$ & $\mathrm{M}$ & $\mathrm{H}$ & $\mathrm{M}$ & $\mathrm{H}$ & $\mathrm{M}$ \\
$15-30$ & - & - & 1 & - & - & 1 & - & 2 \\
$31-50$ & - & - & 2 & - & - & 1 & 1 & - \\
+50 & 1 & - & 1 & 1 & - & 1 & - & - \\
\hline
\end{tabular}

No intuito de manter um paralelismo entre os dados dos dois corpora, optamos por considerar somente os dados referentes aos doze informantes que apareceram nos dois tempos da Amostra. Embora este procedimento tenha reduzido o número de dados, parece o mais adequado por garantir maior precisão no controle do léxico envolvido.

Outro problema que surge no paralelismo entre os dois estados relaciona-se com o tempo de gravação: em virtude de as entrevistas não terem a mesma duração nos dois corpora (as de 1982 têm, cada uma, 60 minutos de gravação, ao passo que as de 1988 têm, em média, 20 minutos), somente consideramos os dados que aparecem nos vinte primeiros minutos das entrevistas do primeiro estado.

A fim de verificar se há correspondência na implementação das inovações nos dois estados da Amostra, analisamos os dados do fator Categoria Gramatical em dois tempos. Observem-se as Tab. 5 e 6:

TABELA 5

Categoria Gramatical em dois tempos nas aféreses

\begin{tabular}{c|cc|cc}
\hline & \multicolumn{2}{|c|}{1982} & \multicolumn{2}{c}{1988} \\
verbos & $67 / 210$ & $32 \%$ & $34 / 128$ & $25 \%$ \\
adjetivos & $9 / 27$ & $31 \%$ & $6 / 32$ & $17 \%$ \\
substantivo & $5 / 24$ & $22 \%$ & $5 / 24$ & $12 \%$ \\
advérbios & $5 / 60$ & $10 \%$ & $6 / 59$ & $9 \%$ \\
preposição & $6 / 35$ & $17 \%$ & $12 / 42$ & $11 \%$ \\
\hline
\end{tabular}

TABELA 6

Categoria Gramatical nas próteses

\begin{tabular}{c|ccc|cc}
\hline \multirow{2}{*}{ verbos } & \multicolumn{2}{|c|}{1982} & \multicolumn{2}{c}{1988} \\
adjetivos & $22 / 127$ & $28 \%$ & $12 / 94$ & $12 \%$ \\
substantivo & $2 / 9$ & $27 \%$ & $1 / 9$ & $10 \%$ \\
advérbios & $1 / 8$ & $12 \%$ & $0 / 5$ & $0 \%$ \\
preposição & - & - & - & - \\
\hline
\end{tabular}

Os resultados das Tab. 5 e 6, via Tempo Real, realmente confirmam as expectativas do diagnóstico via Tempo Aparente: na verdade, os verbos e adjetivos abrem as portas para a mudança, seguidos pelos substantivos, preposições e advérbios, nesta ordem. 
A rota trilhada pela mudança em /a/ inicial parece ter nos verbos e adjetivos deverbais as primeiras vítimas da mudança.

Através dos resultados das Tab. 5 e 6 podemos chegar a alguns aspectos dos parâmetros sociais. Os percentuais das Tab. 5 e 6 indicam, à primeira vista, que aférese e prótese se constituem em mudança em progresso, na direção de $\varnothing \rightarrow / a /$, nas aféreses, e $/ a / \rightarrow \emptyset$, nas ptóteses, caminhando da variante não padrão e estigmatizada para a padrão, uma vez que a taxa de variação tende a ser mais alta no primeiro estado.

Por outro lado, não podemos prognosticar aférese e prótese como fenômenos de mudança em progresso (ao contrário, em trabalho anterior (Gonçalves, 1989) verificamos que se trata de variação estável), uma vez que os números parecem revelar um processo geracional, no qual existe uma certa confluência de fatores sociais refreando ou inibindo o avanço da variante não padrão.

Na verdade, o que acontece é uma modificação bastante significativa na configuração da Amostra: a maioria dos falantes, no segundo estado, além, é claro, de mudar de faixa etária, mudou de nível de escolarização. Desta forma, os movimentos pessoais dos informantes, como, por exemplo, ingresso no mercado de trabalho (como acontece com 4 dos 12 informantes), influenciam diretamente num maior grau de conscientização a respeito das formas cultas da língua. Portanto, há uma série de fatores sociais que interagem para, juntos, refrear a inovação em direção às variantes não padrão.

\section{Formalidade do item}

Para analisar a questão da formalidade dos itens, procedemos a uma distinção binária opondo os itens $\mid+$ formal| aos $\mid$ formal|. Desta forma, para cada item, correlacionamos, no corpus, um par semanticamente correspondente, atribuindo maior formalidade a um e menor a outro. Valendo-nos de nossa intuição, somente aplicamos a marca $\mid+/$-formal| àqueles pares em que houve equiparação de significado bastante próxima, embora saibamos que inexistem sinônimos perfeitos. Assim, no par acontecer/suceder, por exemplo, atribuímos a marca $\mid+$ formal $\mid$ ao segundo, em oposição ao primeiro, que recebeu o rótulo de $\mid-$ formal|. $O$ mesmo se deu com acabar/findar, aparecer/surgir, agarrar/segurar, entre outros pares existentes no léxico dos corpora analisados, sempre atentando para o contexto, no intuito de verificar se eles realmente haviam sido empregados com sentido equivalente.

Essa caracterização traz alguns problemas: a) o já pequeno número de itens referentes ao corpus fica ainda mais reduzido, sendo impossível agrupar um equivalente semântico, dentro dos corpora utilizados, para todo item lexical; b) no emparelhamento de itens, o critério da formalidade não se aplica aos nomes próprios e a alguns nomes comuns. Ora, como é possivel estabelecer um par semanticamente correspondente a substantivos como Alemanha e advogado, por exemplo, atribuindo-lhes maior ou menor formalidade? Com efeito, a maioria dos substantivos não pôde ser analisada; c) além disso, alguns pares tinham equivalência semântica tão duvidosa que preferimos não considerá-los, excluindo-os do cômputo final dos resultados.

Ainda assim, a análise quantitativa mostrou-se reveladora. Observe-se que, nas Tab. 7 e 8, a seguir, dos 39 pares agrupáveis nas aféreses, 30 itens com a marca - formal| foram os mais afetados. Por outro lado, dos 18 pares de itens protéticos ou potencialmente protéticos, apenas 5 itens $\mid$ - formal| foram os mais afetados. 
TABELA 7

Relação entre grau de afetamento por aférese e formalidade do item

\begin{tabular}{c|c|c}
\hline \multicolumn{3}{c}{$\begin{array}{c}\text { Itens afetados } \\
\text { total de itens }\end{array}$} \\
\hline $1+$ formal | & $09 / 39$ & 23 \\
$\mid$ - formal $\mid$ & $30 / 39$ & 77 \\
\hline
\end{tabular}

TABELA 8

Relação entre afetamento por prótese e formalidade do item

\begin{tabular}{c|c|c}
\hline & \multicolumn{1}{c}{$\begin{array}{c}\text { Itens afetados } \\
\text { total de itens }\end{array}$} \\
\hline $\mid+$ formal | & $13 / 18$ & 72 \\
$\mid$ - formal $\mid$ & $05 / 18$ & 28 \\
\hline
\end{tabular}

Observe-se nas Tab. 9 e 10, a seguir, que a quantificação da variável, feita pelo número de dados dos itens lexicais, mostra resultados numéricos bastante semelhantes.

TABELA 9

Relação entre afetamento por aférese e formalidade do item (controle por dados)

\begin{tabular}{c|c|c}
\hline \multicolumn{3}{c}{$\begin{array}{c}\text { Itens afetados } \\
\text { total de itens }\end{array}$} \\
\hline $\mid+$ formal $\mid$ & $026 / 272$ & 10 \\
\hline - formal $\mid$ & $682 / 1582$ & 43 \\
\hline
\end{tabular}

TABELA 10

Relação entre afetamento por prótese e formalidade do item (controle por dados)

\begin{tabular}{c|c|c}
\hline \multicolumn{3}{c}{$\begin{array}{c}\text { itens afetados } \\
\text { total de itens }\end{array}$} \\
\hline |+ formal | & $48 / 189$ & 2 \\
|- formal | & $22 / 201$ & 1 \\
\hline
\end{tabular}

Desta forma, percebemos que os itens mais afetados por aférese são os $\mid$ - formal|, ao passo que nas próteses os mais afetados são os |+ formal|. Podemos afirmar, assim, que a variável Formalidade do Item regula o léxico envolvido em direções contrárias, fazendo com que aférese e prótese se apresentem como fenómenos inversamente proporcionais. 


\section{Freqüência do Item}

A variável Frequência já se mostrou relevante regulador lexical em diversos trabalhos que seguem a orientação difusionista, como o de Phillips (1984) e o de Mollica (1989), por exemplo. Para verificar a influência da freqüência dos itens lexicais nos fenômenos de aférese e prótese, procedemos a uma divisão de ordem ternária que separou os itens em três faixas de ocortências: a) de 1 a 5 ocorrências (frequência baixa); b) de 6 a 15 ocorrências (frequiência média); c) com mais de 15 ocortências (frequiência alta). Nestas faixas aparecem, respectivamente, os itens alimentar e sossegar, agarrar e viciar, e agüentar, e voar.

\section{TABELA 11}

Relação entre afetamento por aférese e frequiência do item

\begin{tabular}{c|c|c}
\hline \multicolumn{3}{c}{$\begin{array}{c}\text { Itens afetados } \\
\text { total de itens }\end{array}$} \\
\hline $1-5$ ocs. & $15 / 150$ & 10 \\
$6-15$ ocs & $30 / 61$ & 49 \\
+ de 15 ocs. & $29 / 31$ & 93 \\
\hline
\end{tabular}

TABELA 12

Relação entre afetamento por prótese e frequiência do item

\begin{tabular}{c|c|c}
\hline \multicolumn{3}{c}{$\begin{array}{c}\text { Itens afetados } \\
\text { total de itens }\end{array}$} \\
\hline $1-5$ ocs. & $18 / 33$ & 54 \\
$6-15$ ocs & $09 / 24$ & 37 \\
+ de 15 ocs. & $06 / 29$ & 20 \\
\hline
\end{tabular}

Observe-se, por outro lado, que os resultados das Tab. 13 e 14, a seguir, confirmam a proporcionalidade inversa nos dois fenômenos. Nestas Tabelas há o cruzainento das categorias gramaticais nas três faixas de frequiência. Pode-se perceber que as categorias gramaticais apresentam a mesma tendência nas três faixas de freqüência, qual seja, afetamento maior nos verbos, seguido pelos adjetivos e substantivos. 
TABELA 13

Relação entre freqüência do item e categoria gramatical nas aféreses

\begin{tabular}{|c|c|c|c|c|c|c|c|c|}
\hline & \multicolumn{2}{|c|}{$\begin{array}{c}1-5 \\
\text { ocorrências }\end{array}$} & \multicolumn{2}{|c|}{$\begin{array}{c}\text { 6-15 } \\
\text { ocortências }\end{array}$} & \multicolumn{2}{|c|}{$\begin{array}{c}+15 \\
\text { ocorrências }\end{array}$} & \multirow{2}{*}{\multicolumn{2}{|c|}{$\begin{array}{c}\text { Total } \\
\text { apl/tot. } \%\end{array}$}} \\
\hline & apl/tot. & $\%$ & apl/to & $\%$ & apl/tot & $\%$ & & \\
\hline verbos & $10 / 60$ & 17 & $21 / 40$ & 53 & $16 / 17$ & 94 & $47 / 117$ & 40 \\
\hline adjetivos & $1 / 26$ & 12 & $4 / 9$ & 44 & $5 / 5$ & 100 & $10 / 40$ & 25 \\
\hline substantivos & $4 / 43$ & 9 & $5 / 10$ & 50 & $4 / 4$ & 100 & $13 / 57$ & 23 \\
\hline advérbios & $0 / 7$ & 0 & $0 / 1$ & 0 & $2 / 3$ & 67 & $2 / 11$ & 18 \\
\hline preposições & $0 / 1$ & 0 & $0 / 1$ & 0 & $1 / 5$ & 20 & $1 / 7$ & 14 \\
\hline
\end{tabular}

TABELA 14

Relação entre freqüência do item e categoria gramatical nas próteses

\begin{tabular}{|c|c|c|c|c|c|c|c|c|}
\hline & \multicolumn{2}{|c|}{\begin{tabular}{c}
\multicolumn{1}{c}{$1-5$} \\
ocortências \\
apl/tot. \%
\end{tabular}} & \multicolumn{2}{|c|}{$\begin{array}{c}\text { 6-15 } \\
\text { ocortências } \\
\text { apl/tot. \% }\end{array}$} & \multicolumn{2}{|c|}{$\begin{array}{l}+15 \\
\text { ocorrências } \\
\text { apl/tot. \% }\end{array}$} & \multicolumn{2}{|c|}{$\begin{array}{c}\text { Total } \\
\text { apl/tot. } \%\end{array}$} \\
\hline verbos & $13 / 17$ & 76 & $5 / 17$ & 29 & $6 / 20$ & 31 & $26 / 54$ & 48 \\
\hline adjetivos & $4 / 15$ & 27 & $3 / 5$ & 60 & 0 & 10 & $07 / 21$ & 33 \\
\hline substantivos & $1 / 1$ & 100 & $1 / 2$ & 50 & $0 / 8$ & 0 & $02 / 11$ & 18 \\
\hline advérbios & - & & & & & & - & \\
\hline preposições & - & & & & & & - & \\
\hline
\end{tabular}

Os resultados obtidos na quantificação da variável Freqüência mostram que, também aqui, aférese e prótese caminham em direções opostas: os itens mais afetados por aférese são aqueles com maior freqüência no corpus, como evidenciam os resultados da Tab. 11, onde observamos que o grau de afetamento aumenta à medida que se aumenta a frequiência do item. Nas próteses, diferentemente, o grau de afetamento decresce quando se aumenta a frequieencia do item. Os resultados das próteses são diametralmente opostos aos das aféreses, o que nos leva a corrobotar a tese da proporcionalidade inversa entre os fenômenos, pois o fator Freqüência comprova que há "lógicas lexicais" diferentes para o afetamento ou não por aférese ou prótese.

\section{CONCLUSÃO}

A estrutura elementar de aférese e prótese pode ser definida como uma relação inversa entre os dois termos, uma vez que repousa sobre uma distinção binária do tipo $+/ a / ;>/ a /$, caracterizada pela oposição resultante da presença e da ausência desse traço fônico, que vai gerar, a princípio, uma relação de simetria entre os dois fenômenos: inversão e queda de /a/ são inversamente proporcionais na medida em que permitem condicionamentos convergentes do ponto de vista funcional. Esquematicamente, teriamos a seguinte correspondência. 


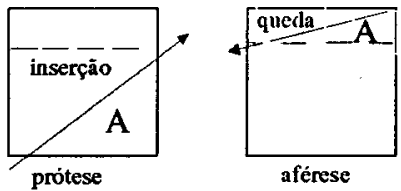

Constatamos que um grupo de itens com caracteres mórficos comuns (a presença do/a/ inicial como prefixo de negação) freia a inovação (que é o cancelamento do/a/), resistindo à mudança. Essas exceções não podem ser explicadas por empréstimo-analogia, como postulam os neogramáticos, mas por fatores de natureza morfo-lexical.

Por outro lado, os parâmetros lexicais analisados regulam o afetamento de $+/ a /$ e - $/ \mathrm{a} /$ em direções contrárias, atingindo diferentemente as fronteiras aferéticas e protéticas. Assim, podemos afirmar que os fenômenos estão se difundindo diversamente no sistema, instalando-se gradualmente no léxico da lingua através de variações condicionadas por fatores quer de natureza estrutural, quer extra-lingüistica (cf. Gonçalves, 1989).

Por outro lado, com os resultados das variáveis lexicais analisadas, podemos concluir que aférese e prótese são duas faces de un mesmo processo, constituindo-se em verso e reverso no enantiomórfico relacionamento de correspondências através do espelho fonológico.

\section{REFERÊNCIAS BIBLIOGRÁFICAS}

BECHARA, Evanildo. Moderna gramática brasileira. São Paulo: Nacional 1975.

CHEN, M., WANG, W.S-Y. Sound Change: actuation and implementacion. Language, v.51, n.2, p.255-279, jun. 1975.

CUNHA, Celso Ferreira da. Gramática da língua portuguesa. 5. ed. Rio de Janeiro MEC/FENAME.

GONÇALVES, Carlos A. V. A variação em aférese e prótese no português carioca. Rio de Janeiro: UFRJ/FAPERJ, 1989. (Relatório - mimeogr.)

LABOV, William. Resolving the neogrammarian controversy. Language v. 57, n.2, 267-308, jun. 1981.

LIMA, Joana d'Arc de Matos. O -r em dois tempos: ou no princípio era o verbo. In ENCONTRO NACIONAL DA ANPOLL, 5, 1990, Recife. Comunicação apresentada... Recife: UFPE, 1990. 15 p. (mimeogr.)

MOLLICA, Maria Cecília de Magalhães. Queísmo e dequeísmo no português do Brasil. Rio de Janeiro : UFRJ, 1989. 306 p. Tese (Doutorado) - Faculdade de Letras, Universidade Federal do Rio de Janeiro.

OLIVEIRA, Marco A. de. Aspectos da difusão lexical. In: ENCONTRO NACIONAL DA ANPOLL, 5, 1990, Recife. Comunicação apresentada... Recife: UFPE, 1990. 12 p. (Mimeogr.) 
OLIVEIRA, Marco A. de. The neogrammarian controversy revisted. InternationalJournal of the Sociology of Language, Berlin, v. 89, p. 93-105, 1991.

PHILLIPS, B. S. Word frequency and the acuation of sound change. Language , v. 60, n. 2, p. 320-42, junho, 1984.

ROCHA LIMA, Carlos Henrique da. Gramática normativa da língua portuguesa 10. ed. Rio de Janeiro: Ao Livro Técnico, 1979.

SCHANE, Sanford A. Fonologia gerativa. Rio de Janeiro: Zahar, 1975.

TARALLO, Fernando. A estrutura da variação: do falante-ouvinte real ao FalanteOuvinte Real. D. E. L. T. A., São Paulo, v. 6 n. 2., p. 195-222 nov. 1990.

WANG, W. S-Y. Competing changes as a cause of residue. Language, v. 45, n.1, p. 9-25, mar. 1969. 